\title{
DEVELOPMENT OF A VIRTUAL MUSEUM INCLUDING A 4D PRESENTATION OF BUILDING HISTORY IN VIRTUAL REALITY
}

\author{
T. P. Kersten ${ }^{a *}$, F. Tschirschwitz ${ }^{\text {a }}$, S. Deggim ${ }^{\text {a }}$ \\ a HafenCity University Hamburg, Photogrammetry \& Laser Scanning Lab, Überseeallee 16, D-20457 Hamburg, Germany - \\ (Thomas.Kersten, Felix.Tschirschwitz, Simon.Deggim)@hcu-hamburg.de
}

\author{
Commission II
}

KEY WORDS: 3D, 4D, construction phases, HTC Vive, modelling, reconstruction, virtual museum, virtual reality

\begin{abstract}
:
In the last two decades the definition of the term "virtual museum" changed due to rapid technological developments. Using today's available $3 \mathrm{D}$ technologies a virtual museum is no longer just a presentation of collections on the Internet or a virtual tour of an exhibition using panoramic photography. On one hand, a virtual museum should enhance a museum visitor's experience by providing access to additional materials for review and knowledge deepening either before or after the real visit. On the other hand, a virtual museum should also be used as teaching material in the context of museum education. The laboratory for Photogrammetry \& Laser Scanning of the HafenCity University Hamburg has developed a virtual museum (VM) of the museum "Alt-Segeberger Bürgerhaus", a historic town house. The VM offers two options for visitors wishing to explore the museum without travelling to the city of Bad Segeberg, Schleswig-Holstein, Germany. Option a, an interactive computer-based, tour for visitors to explore the exhibition and to collect information of interest or option b, to immerse into virtual reality in 3D with the HTC Vive Virtual Reality System.
\end{abstract}

\section{INTRODUCTION}

A function of a museum is to aide non-specialists in understanding information and context via an interaction of short duration. Ideally museums should also deepen visitors' interest in the subjects that they present. In accordance with their educational mission, museums must constantly present and represent complex issues in ways that are both informative and entertaining, thus providing access to a wide target audience. Visitors with prerequisite knowledge, prior experiences, as well as associated individual interests and objective tend to take a more active role in engaging with museums (Reussner, 2007). Today, these fundamental ideas are increasingly being implemented through so-called "serious games", which embed information in a virtual world and create an entertaining experience through the flow of and interaction with the game (Mortara et al. 2014).

For the museum field, the consolidation and implementation of culture and information technology is often called Virtual Museum (VM). The definition of a Virtual Museum is, however, not fixed. Since the 1990s many different definitions for a VM have been published with significant differences depending on the contemporary status of information and communication technology (ICT) (Shaw 1991; Schweibenz 1998; Jones \& Christal 2002; Petridis, et al. 2005; Ivarsson 2009; Styliani et al. 2009). According to V-MusT (2011) "a virtual museum is a digital entity that draws on the characteristics of a museum, in order to complement, enhance, or augment the museum experience through personalization, interactivity and richness of content. Virtual museums can perform as the digital footprint of a physical museum, or can act independently ...". Pujol \& Lorente (2013) use the term VM to refer to a digital spatial environment, located in the WWW or in the exhibition, which reconstructs a real place and/or acts as a knowledge metaphor, and in which visitors can communicate, explore and modify spaces and digital or digitalized objects. Pescarin et al. (2013) evaluated VMs. They found that the impact of interactive applications on the user seems to be depend on the capability of the technology to be "invisible" and to allow a range of possibilities for accessing content. To achieve this, VMs need a more integrated approach between cultural content, interfaces, and social and behavioural studies. However, VMs are using different media, such as text, images, sound and animated 3D models, to act as an interactive platform for the informative supplement of the real museum visit (Samida 2002). The design of the VM varies from simple Web pages (Bauer 2001) to panorama-based virtual tours (Kersten \& Lindstaedt 2012) to interactive apps for smartphones or tablets (Gütt 2010). A good example for a VM is AfricanFossils.org, which presents as a virtual lab a spectacular digital collection of fossils and artefacts found mostly at Lake Turkana in East Africa in the Internet (http://africanfossils.org/). The digital collection of animals, human ancestors, and ancient stone tools offers a unique tool for

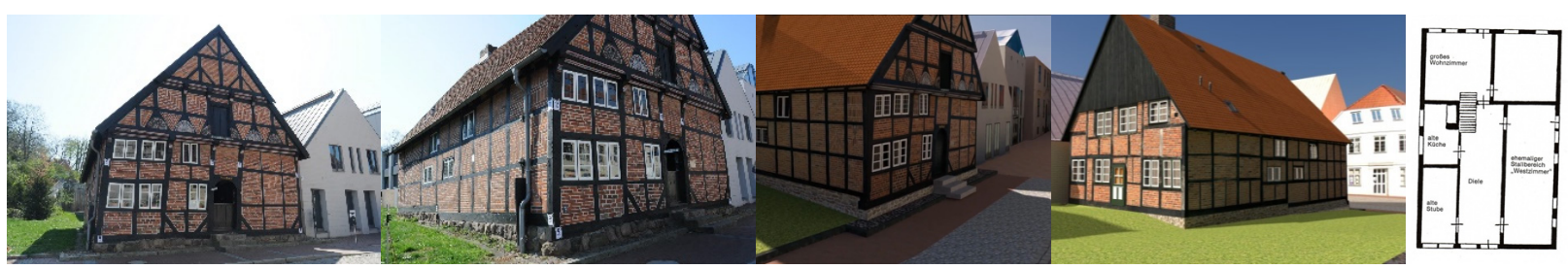

Figure 1. Front view of the Old-Segeberg town house (left), its textured 3D model (centre) and plan of the ground floor (right)

\footnotetext{
* Corresponding author
} 
scholars and enthusiasts to explore and interact with the collection online. Another example for a digital collection of exhibits is Smithsonian X 3D (https://3d.si.edu/), for which various $3 \mathrm{D}$ capture methods are applied to digitize iconic collection objects. The idea of Smithsonian X 3D is to promote the use of 3D data for many applications.

A VM that is retrievable on the Internet would offer the possibility of making a time- and location-independent virtual visit to the museum. It would also facilitate preparation for and evaluation of an actual museum visit, as this medium stimulates the attention of the visitor while also providing further information. The great strength of a VM is the ability to utilise current ICT to supplement conventional exhibition techniques via the presentation and integration of content into the real exhibition, thus significantly contributing to a visitor's understanding.

The Laboratory for Photogrammetry \& Laser Scanning of the HafenCity University Hamburg has developed a VM for the museum of Old-Segeberg town house (Alt-Segeberger Bürgerhaus) as an interactive tour for a windows-based computer system and as a virtual reality application in 3D using the Virtual Reality System HTC Vive. Based on this concrete example, this contribution provides examples of how museums can fulfil the technological and media requirements in the 21 st century using detailed geo data and appropriate ICT.

\section{THE OLD-SEGEBERG TOWN HOUSE}

Even at the end of the $19^{\text {th }}$ century, the Old-Segeberg town house (Fig. 1), located in the city of Bad Segeberg $40 \mathrm{~km}$ northeast of Hamburg, was already known as the oldest house of the city. Today it is one of only a few well-preserved, small urban town houses from the beginning early modern period in the federate state of Schleswig-Holstein. In the new installed council book from 1539, the building was already included in the historic rent listing. After Segeberg was almost completely destroyed in June 1534 during the Count feud from 1533-1536/37, the town house was re-established in 1541. Firstly, as a simple hall building with a single-storey, in-frame construction with brick-bracing to the property that is today's Lübecker Straße No. 15. The method of construction was poor and building materials from neighbouring ruined properties (e.g. in the roof framing) were partly recycled. However, the basic structure of the framework construction was established from fresh wood (oak). It is presumed that the cellar with walls, constructed from boulders, hailed from the medieval predecessor building (Reimers \& Hinrichsen 2015). In the following centuries the house was extended and converted several times.

With support of a historian and based on historical sources (Reimers \& Hinrichsen 2015) six construction phases of the building could be identified. These were each modelled in AutoCAD and are presented in chronological order in Figures 2 and 3, from left to right.: (1) construction work (1541), (2) the first extension (around 1587), (3) Stall addition at the south front (before 1805), (4) extension of the living space (from 1814), (5) renovation and conversion of the front façade (ca. 1890), and (6) refurbishment of the building and conversion to a museum (1963/64). A detailed description of the six construction phases of the building are presented in Kersten et al. (2014).

After the refurbishment in 1963-64, the building contained the local museum of the City Bad Segeberg. For the next few decades, exhibits from the petty-bourgeois living and working environment of the 19th and 20th centuries were shown in its historic rooms. After the adult education centre (Volskhochschule) Bad Segeberg took over sponsorship of the museum in 2012, it was renamed "Museum Alt-Segeberger Bürgerhaus" and successive permanent exhibitions on the topics "500 years development of civic culture in the mirror of a 470year-old house" and "800 years history of the city of Segeberg from the medieval castle settlement to the modern resort" were hosted.

\section{PROJECT WORKFLOW}

The entire museum Old-Segeberg town house was modelled in $3 \mathrm{D}$ so that visitors could virtually explore the exterior and interior of the building in close relationship to the various exhibits in the museum. Special focus was given to developing visitors' understanding of the complex history of the building via an interactive visualisation of the nearly 500-year-old museum building's extensive construction history.

The project has been roughly divided into three major phases of development (Fig. 4): A) Concept creation and test of all planned functions, B) Modelling and texturing of the Museum, its content and the models for the visualisation of architectural history, and C) Integration into a program and generation of interaction possibilities.
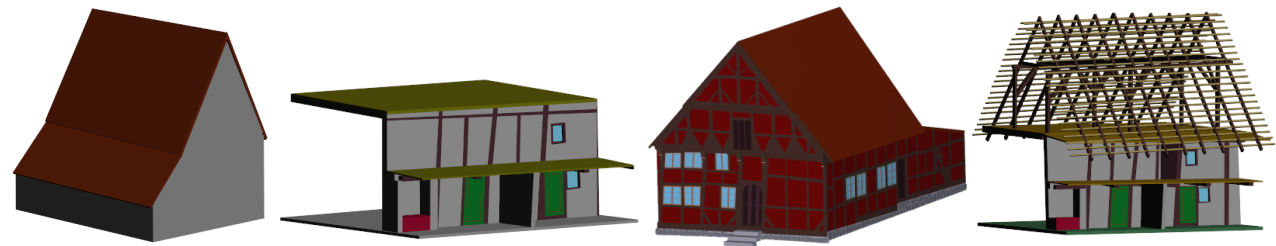

Figure 2. 3D model of Old-Segeberg town house: f.l.t.r. 1541 outside, 1541 inside, 1584-1588 outside and 1584-1588 inside
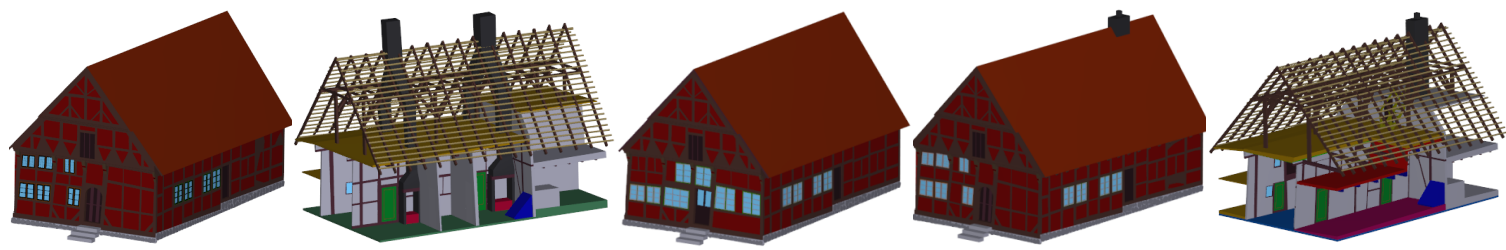

Figure 3. 3D model of Old-Segeberg town house: f.l.t.r. 1814 outside, 1814/1890 inside, 1890 outside and 1964 outside/inside 


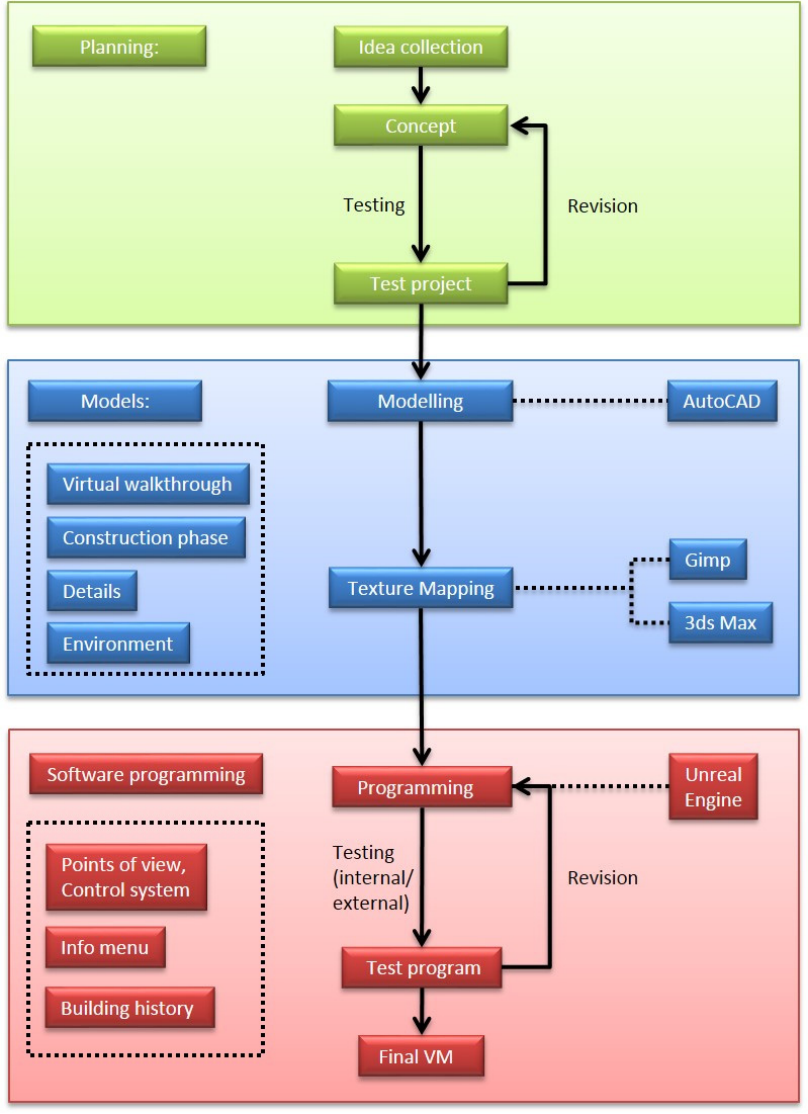

Figure 4. Workflow for the development of the VMs $-\mathrm{A}$ ): concept (top - green), B): modelling (centre - blue) and C): programming (bottom - red)

Existing VMs are typically either digitized collections or virtual tours based on panoramas with little or no interaction. In this work, to further exploit the potential of digital visualisation, the serious games approach was selected because it enabled consideration of the use of elements known from games, such as extensive free movement and the option of looking closer at surroundings or interesting objects/exhibits.

Initially, several methods of control and presentation of information were tested in a rough test model. In later stages, other planned functions were implemented to enable optimal use of the program.

\section{MODELLING}

The 3D object recording was conducted over two separate acquisition campaigns, on 21 April and 2 August 2011, using the IMAGER 5006h terrestrial laser scanner and two digital SLR cameras, Nikon D40 and D90, for the exterior and interior areas, respectively. The base for the development of the virtual museum was this detailed 3D recording of the exterior and interior of the building using digital photogrammetry and terrestrial laser scanning. Intensive 3D CAD modelling, using coloured point clouds from laser scanning and manually-measured photogrammetric 3D points, represented the second stage of activity. For the 3D modelling and visualisation of huge point clouds in AutoCAD, the plug-in PointCloud, from the company Kubit in Dresden, Germany, was used. Using this plug-in, CAD elements, e.g. surfaces such as the half-timbered bars, could be directly digitised in the point cloud. In the oriented images, each object point was measured manually in at least four photos from different camera stations. After the image point measurements were completed for one object element, for example a window, the computed 3D object points for this element were transferred to AutoCAD. There, polylines were generated from these points, and these were later used to generate surfaces. Simple object parts were constructed using geometrical primitives (e.g. cuboid, pyramid, cylinder, cone, circle, ring, etc.), while some more complex object parts were created with the Boolean operators in CAD (union, subtraction and intersection). Kersten et al. (2014) give a detailed description of the data acquisition and modelling of the town house.

Based on this reconstructed 3D model further 3D modelling was carried out to fulfil the requirements for the development of the virtual museum. To bring the interior to life, the most important exhibits, information panels and furnishings were also modelled and these were placed in their appropriate places within the building. Additionally the six different historical construction stages of the Old-Segeberg town house were modelled, in collaboration with the historian Nils Hinrichsen (Director of the Museum Old-Segeberg town house). The appearance of the building, in particular for the early construction phases, is only assigned to parts based on historical scientific evidence collected in recent years. For example, a dendrochronological analysis of individual timbers was conducted, which determines the age of various parts of the building and which could be assigned to the corresponding construction phases (Reimers \& Hinrichsen 2015). For data reduction, the six construction phases were modelled together, i.e. objects, which occur in several construction phases, were created only once and stored in a database, thus allowing utilisation by the program in multiple phases. Fig. 3 shows the first four construction stages and their most distinctive changes from the same perspective. Finally,

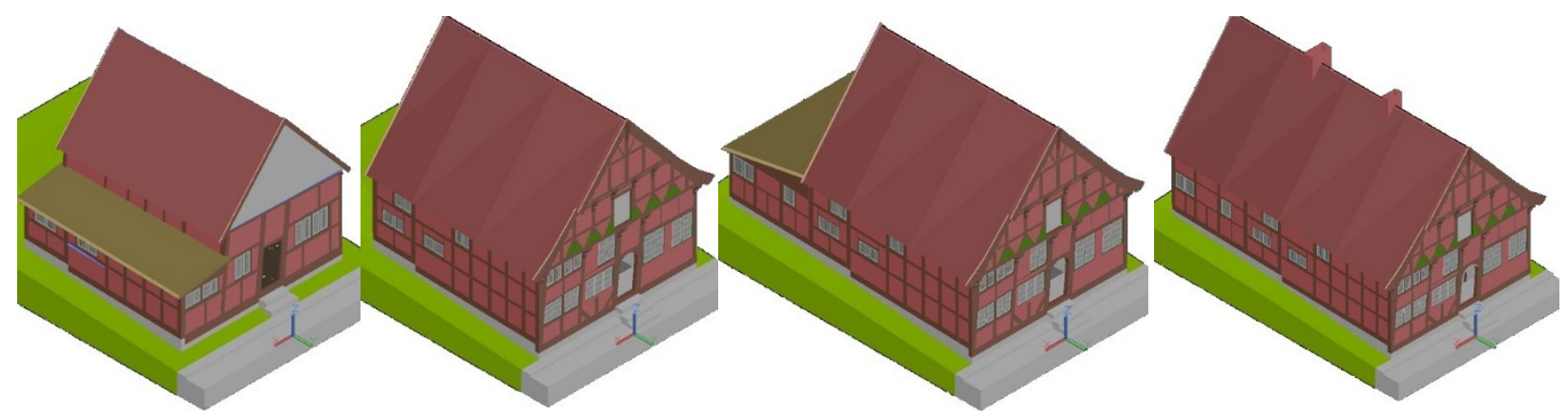

Figure 5. Advanced 3D models of the different construction stages of the town house. From left to right: 1541-1585, 1585 - ca. 1805 , ca. $1805-1814$ and $1814-$ ca. 1890 
based on terrestrial photos and Google Earth data, the environment of the building was also reconstructed to ensure that this historic building was embedded in its urban environment. As a stylistic device, the surrounding buildings were coloured grey to emphasize the museum in the visualisation.

The texture mapping of the model was carried out using the software Autodesk 3ds Max. The photos used for texturing were mainly locally-taken photos. However, textures that were freely available online were also integrated after appropriate editing. Furthermore, bump and alpha textures were used to improve the depth effect and the appearance of details. In total, 239 textures were used for visualisation.

\section{GAME ENGINE UNREAL}

A game engine is a software framework designed for the creation and development of video games for consoles, mobile devices and personal computers. The core functionality typically provided by a game engine includes a rendering engine for $2 \mathrm{D}$ or 3D graphics to display textured 3D models (spatial data), a physics engine or collision detection (and collision response) for the interaction of objects, an audio system to emit sound, scripting, animation, artificial intelligence, networking, streaming, memory management, threading, localisation support, scene graph, and may include video support for cinematics. A game engine controls the course of the game and is responsible for the visual appearance of the game rules. For the development of a virtual museum, game engines offer many necessary concepts with much functionality so that users can interact with the VM.

In the past, the development of game engines was mostly based on the development of a specific game with paid licensing to external game developers. In recent years, however, most of the large engine providers have focused more on the advancement of engines and additionally offer free access for developers. Examples of game engines with free potential use are the engine Unity from Unity Technologies, the CryEngine of the German development studio Crytek, and the engine Unreal from Epic Games (www.epicgames.com). A current overview and comparison of different game engines can be found e.g. in O'Flanagan (2014) and Lawson (2016). The selection of the appropriate engine for a project is based on the provided components mentioned above, the adaptability in the existing work processes as well as special preferences of the (game) developer. In the framework of this project, the game engine Unreal was selected due to the opportunity to develop application and interaction logics using a visual programming language, the so-called Blueprints. Visual programming with Blueprints does not require the writing of machine-compliant source code. Thus it provides opportunities for non-computer scientists to program all functions for a VM using graphic elements. The saving in time associated with this method of software development allows for the generation of additional scenarios and for more intensive user testing. Game engines are, therefore, very well-suited to the development of virtual museums.

\section{VIRTUAL REALITY SYSTEM HTC VIVE}

HTC Vive (www.vive.com) is a virtual reality headset (with a weight of 555 grams, Fig. 6) for room-scale virtual reality. It was developed by HTC and the Valve Corporation, was released on 5 April 2016, and is currently available on the market for EUR 899. Basic components are the headset for the immersive experience, two controllers for user interactions and two "Lighthouse" base stations for tracking the user's movement.

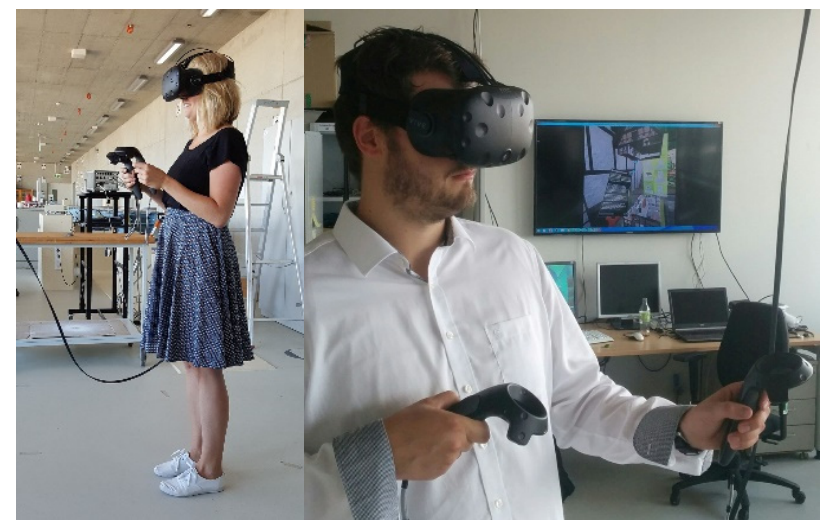

Figure 6 . The virtual reality system HTC Vive in use. The screen in the background shows the same sequence as appears to the user in the VR glasses (right)

The technical specifications of the HTC Vive are summarized in the following: a) two screens with a field of view of approximately 110 degrees, one per eye, each having a display resolution of $1080 \times 1200$ with a refresh rate of $90 \mathrm{~Hz}, \mathrm{~b}$ ) more than 70 sensors including a MEMS (Microelectromechanical systems) gyroscope, accelerometer and laser position sensors, c) 4.6 by $4.6 \mathrm{~m}$ tracking space for user operation using two "Lighthouse" base stations for tracking the user's movement with sub-millimetre precision by emitting pulsed IR lasers, d) SteamVR running on Microsoft Windows as platform/operating system, e) Controller input by SteamVR wireless motion tracked controllers, and f) front-facing camera for looking around in the real world to identify any moving or static object in a room as part of a safety system.

The following technical specification is required as the minimum for the computer to be used: processor Intel ${ }^{\mathrm{TM}}$ Core $^{\mathrm{TM}} \mathrm{i5}-4590$ or AMD FX ${ }^{\mathrm{TM}}$ 8350, graphic card NVIDIA GeForce ${ }^{\mathrm{TM}}$ GTX 1060 or AMD Radeon ${ }^{\mathrm{TM}}$ RX 480, 4 GB RAM, video output 1x HDMI 1.4-connection or DisplayPort 1.2 or newer, 1x USB 2.0connection or newer, operating system Windows ${ }^{\mathrm{TM}} 7$ SP1, Windows $^{\mathrm{TM}} 8.1$ or more up to date or Windows ${ }^{\mathrm{TM}} 10$.

The device uses a gyroscope, accelerometer, and laser position sensor to track the head's movements as precisely as one-tenth of a degree. Wireless controllers in each hand, with precise SteamVR-tracking, enable the user to freely explore virtual objects, people and environments, and to interact with them. The VIVE-controller is specifically designed for VR with intuitive control and realistic haptic feedback. The Lighthouse system uses simple photo sensors on any object that needs to be captured. To avoid occlusion problems, this is combined with two lighthouse stations that sweep structured light lasers within a space.

\section{IMPLEMENTATIONS}

\subsection{Windows-based VM implementation}

The major part of the work dealt with the programming of the user movement in the museum, with information queries and the corresponding animations in the game engine "Unreal Engine". The intuitive handling of the program was an essential prerequisite, allowing also easy access to and use of the VMs for inexperienced PC users (Fig. 7). 


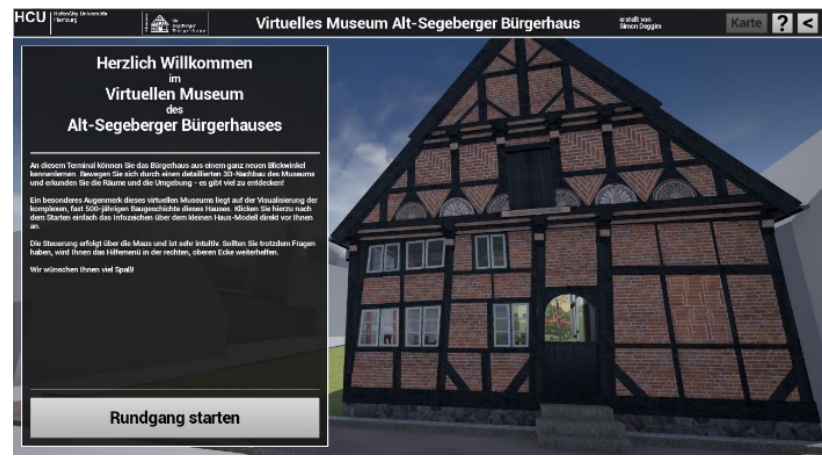

Figure 7. Graphical User Interface for the virtual museum tour

The control of the software is exclusively available via mouse interaction and is based on many well-distributed positions throughout the building, which can be directly selected by clicking on a map or approached using a defined camera path through the $3 \mathrm{D}$ environment. In these positions, the users can freely look around using a $360^{\circ}$ panorama. Users can also zoom in and out, and click on the available information button. As a special highlight of the VM, the visualisation of the building history was realized with a "model in the model" (Fig. 8, Fig. 9 left and Fig. 11 right).

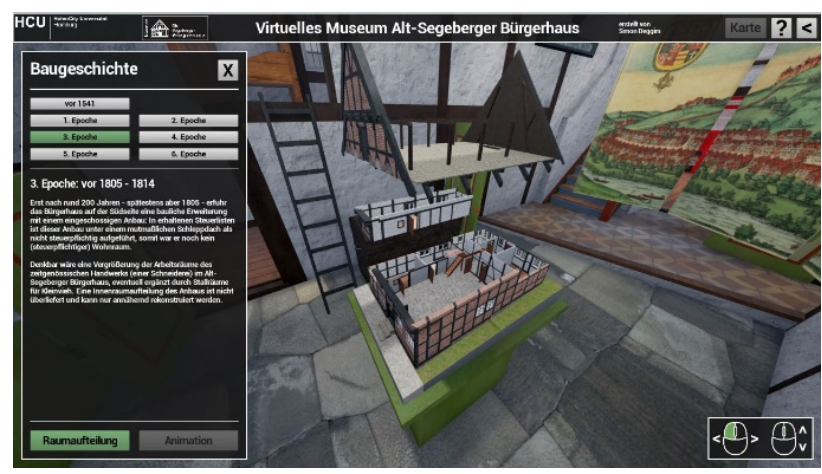

Figure 8. Graphical User Interface for the building history with an animated view into the interior of a construction phase

At one station of the virtual tour, which is located in front of the model, the user can open this model to display and animate, upon request, each of the building states including all related information. The user can look at the building model from all sides using virtual rotation. In addition, with a mouse click, the roof can be removed, the individual floors can be driven apart by animation, and the appearance of the building interior in the respective building phase will be shown (Fig. 5). Each room can now be selected to display information about the development of building use. Furthermore, it is possible to start an animated transition from the previous construction phase, which shows and describes the structural changes to the next state for each construction phase. These animations required a subdivision of all 3D models into 387 smaller objects, to precisely control the movement of the objects for each animation. In the animation, the user is guided by predefined camera movements to appropriate viewpoints.

Menus and information boards, which can be opened during the individual tour using the info button placed next to the selected objects, were created for the exhibits. These menus include brief explanations and mostly a figure that can be enlarged via mouse click. Some information is directly imparted using detailed pointof-view shots in the $3 \mathrm{D}$ environment. In such cases, cameras were distributed in the whole Museum at appropriate points. These can also be selected using the info button.

Finally, comfort functions were created such as tool tips, an overview map and a help menu. For quality assurance, the VM program has been tested by several people with different PC experience to subsequently customize the software details.

\subsection{Virtual Reality Application with HTC Vive}

Based on the modelled and textured 3D data in the game engine, an immersive virtual reality visit was developed utilizing the new Virtual Reality System HTC Vive. The visit offers the possibility of experiencing the museum and the history of the building from a real person's point of view and interaction scheme. For this purpose, the controlling positions have been replaced by the possibility of free movement by the user. To bridge long distances in the virtual object, a teleportation function is available for the navigation of the user (Fig. 10).

The users' hands can interact with various components of the virtual world to control the building's presentation. The object selection and menu operation is enabled via a "laser beam", which is controlled by the motion controller (Fig. 11 left). The highlight of the virtual museum visit is the animation of the architectural building history, which is vividly represented by the HTC Vive glasses directly in front of the visitor's eyes on the basis of the 3D models (Fig. 6). Different historically-confirmed construction phases are visibly demonstrated in $3 \mathrm{D}$ and changes are illustrated by transition animations.
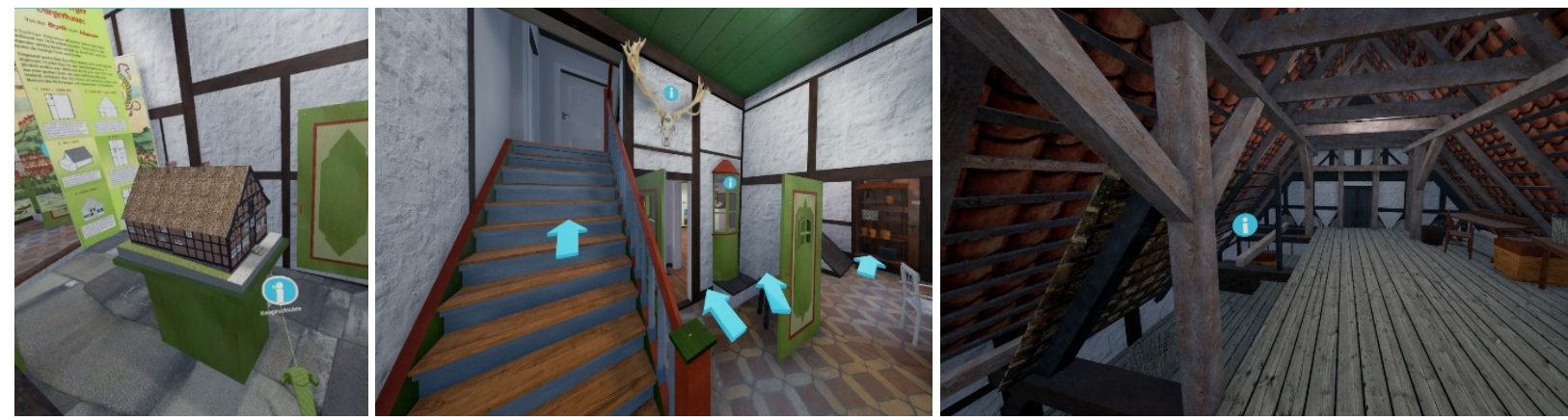

Figure 9. Impressions from the 3D environment of the virtual museum Old-Segeberg town house including the model of the building (left), the stairways to the attic (centre) and a view at the attic (right) 


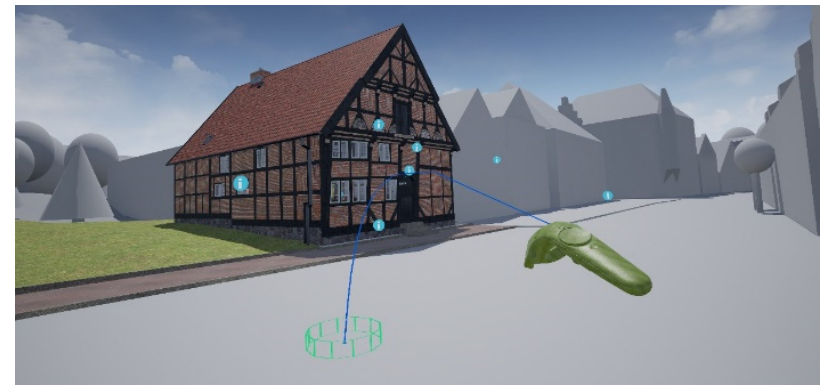

Figure 10. Navigation in the virtual museum Old-Segeberg town house using the developed teleportation function for the Virtual Reality System HTC Vive
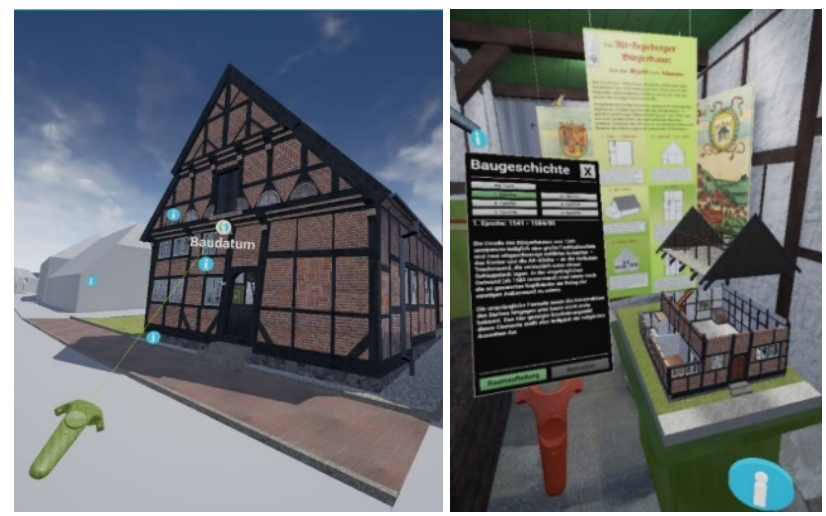

Figure 11. The virtual museum Old-Segeberg town house in the Virtual Reality System HTC Vive as an intense experience. Menu navigation with green motion controller by "laser beam" (left) and second red controller for the information menu (right)

\section{CONCLUSION AND OUTLOOK}

This contribution described the successful development and implementation of a Virtual Museum for the museum OldSegeberg town house with two options: a) interactive software application for windows-based computer systems and b) virtual reality application for the VR system HTC Vive. Many visitors and participants have tried and tested the VM by using both a windows-based computer system and the VR system HTC Vive. The Old-Segeberg town house can look back on 475 years of architectural development, identified and explained in form of animations, which are the highlights of the virtual museum. The developed computer program contains 13 guided viewpoints distributed at important positions in the museum and 52 info menus with detailed information for visiting the virtual museum. The program has a size of 500 MByte and is executable as a standalone program on Windows operating systems. It is developed in the game engine Unreal, which offers, not only complex visualisations of $3 \mathrm{D}$ objects, but also provides every programming tool necessary for creating extensive interactions between the user and the environment. To make this program accessible for the visitors, a PC-terminal will be provided in the Old-Segeberg town house in the next museum season. It allows, in addition to the current exhibition, a multimedia interaction with the history of the city and the building. Thus, based on this building, it carries out an important educational contribution for the urban development of Bad Segeberg and about 500 years of housing tradition in Schleswig-Holstein. Developed entirely in $3 \mathrm{D}$, the $\mathrm{VM}$ is unique in this form in Germany as an informative component of a museum.
The VR application using the HTC Vive gives the opportunity to check the geometric quality of the modelled 3D data during the VR visualisation. However, walking through the virtual museum of the Old-Segeberg town house, collecting all of the information in the exhibition and seeing all of the different animations, which explain the construction changes of the building over the centuries, is a very immersive experience.

The emerging technology Augmented Reality also offers great potential by combining the advantages of a VM with the real museum visit. It also enables the museum visit in situ using a Smartphone or tablet for digital superimposition of the current state with a historic building state, for example at sites of (former) historic ground (Canciani et al. 2016).

In general, VR applications or systems can also be used outside the museum context - for example, for product visualisations, for facility management, for trade fairs or for tutorials of workflows (e.g. for the fire brigade).

\section{ACKNOWLEDGEMENTS}

The significant support of the historian Nils Hinrichsen (Head of the museum Alt-Segeberger Bürgerhaus) is gratefully acknowledged.

\section{REFERENCES}

Bauer, T., 2001. Museen und Internet. Museologie Online, 3, 112-161.

Canciani, M., Conigliaro, E., Del Grasso, M., Papalini, P. \& Sacconea, M., 2016. 3D Survey and Augmented Reality for Cultural Heritage. The Case Study of Aurelian Wall at Castra Praetoria in Rome. ISPRS-International Archives of the Photogrammetry, Remote Sensing and Spatial Information Sciences, 41 (B5), 931-937.

Gütt, I., 2010. Smartphone-Applikationen im Museumsbereich. Bachelor thesis, Studiengang Museumskunde, Fachbereich Gestaltung, HTW Berlin, 74 p.

Ivarsson, E., 2009. Definition and Prospects of the Virtual Museum. Master Thesis, Uppsala University, http://www.elinivarsson.com/docs/virtual_museums.pdf.

Jones, G. \& Christal, M., 2002. The future of virtual museums: On-line, immersive 3-D environments. Created Realities Group, 2002 (9), 1-12.

Kersten, T. \& Lindstaedt, M., 2012. Virtual Architectural 3D Model of the Imperial Cathedral (Kaiserdom) of Königslutter, Germany through Terrestrial Laser Scanning. EuroMed 2012 Int. Conference on Cultural Heritage, Ioannides, M.; Fritsch, D.; Leissner, J.; Davies, R.; Remondino, F.; Caffo, R. (Eds.), Lecture Notes in Computer Science (LNCS), Volume 7616, SpringerVerlag Berlin Heidelberg, 201-210.

Kersten, T., Hinrichsen, N., Lindstaedt, M., Weber, C., Schreyer, K. \& Tschirschwitz, F., 2014. Architectural Historical 4D Documentation of the Old-Segeberg Town House by Photogrammetry, Terrestrial Laser Scanning and Historical Analysis. Progress in Cultural Heritage. Documentation, Preservation, and Protection, 5th International Conference, EuroMed 2014, Limassol, Cyprus, November 3-8, 2014, Ioannides, M., Magnenat-Thalmann, N., Fink, E., Zarnic, R., Yen, A.-Y., Quak, E. (Eds.), Lecture Notes in Computer Science (LNCS), Volume 8740, Springer International Publishing Switzerland 2014, pp. 35-47. 
Lawson, E., 2016. Game Engine Analysis. https://www.gamesparks.com/blog/game-engine-analysis/ (last access January 12, 2017).

Mortara, M., Catalano, C. E., Bellotti, F., Fiucci, G., HouryPanchetti, M. \& Petridis, P., 2014. Learning cultural heritage by serious games. Journal of Cultural Heritage, 15(3), 318-325.

O'Flanagan, J., 2014. Game Engine Analysis and Comparison. https://www.gamesparks.com/blog/game-engine-analysis-andcomparison/ (last access January 11, 2017).

Pescarin, S., Pagano, A., Wallergård, M., Hupperetz, W. \& Ray, C., 2013. Evaluating virtual museums: Archeovirtual case study. Archaeology in the Digital Era, Proceedings of the 40th Annual Conference of Computer Applications and Quantitative Methods in Archaeology (CAA), 74-82.

Petridis, P., White, M., Mourkousis, N., Liarokapis, F., Sifniotis, M., Basu, A. \& Gatzidis, C., 2005. Exploring and interacting with virtual museums. Proceedings of the 33rd Annual Conference of Computer Applications and Quantitative Methods in Archaeology (CAA), Figueiredo, A. \& Gonçalo Leite, V. (eds) 2007.

Pujol, L. \& Lorente, A., 2013. The Virtual Museum: a Quest for the Standard Definition. Archaeology in the Digital Era, Proceedings of the 40th Annual Conference of Computer Applications and Quantitative Methods in Archaeology (CAA), 40-48.
Reimers, H. \& Hinrichsen, N., 2015. Das Alt-Segeberger Bürgerhaus. Vom Stadtwohnhaus des 16. Jahrhunderts zum Stadtmuseum im 21. Jahrhundert. Lutherstadt Wittenberg, Torgau und der Hausbau im 16. Jahrhundert, Jahrbuch für Hausforschung, Goer, M., Furrer, B., Klein, U., Stiewe, H. \& Weidlich, A. (Hrsg.), Band 62, 341-355.

Reussner, E., 2007: Wissensvermittlung im Museum - ein überholtes Konzept? Kultur und Management im Dialog, 5, 2023

Samida, S., 2002. Überlegungen zu Begriff und Funktion des „,virtuellen Museums“: Das archäologische Museum im Internet. Museologie Online, 4, 1-58.

Schweibenz, W., 1998. The" Virtual Museum": New Perspectives for Museums to Present Objects and Information Using the Internet as a Knowledge Base and Communication System. Internationales Symposium für Informationswissenschaft ISI, 185-200.

Shaw, J., 1991. The Virtual Museum. Installation at Ars Electrónica. Linz, Austria: ZKM, Karlsruhe.

Styliani, S., Fotis, L., Kostas, K. \& Petros, P., 2009. Virtual museums, a survey and some issues for consideration. Journal of Cultural Heritage, 10(4), 520-528.

V-MusT, 2011. What is a Virtual Museum? Virtual Museum Transnational Network, http://www.v-must.net/virtualmuseums/what-virtual-museum, (last access January 13, 2017). 